\section{Comparative Performance of Air-induction and Conventional Nozzles on an Axial Fan Sprayer in Medium Density Apple Orchards}

\author{
S.J. McArtney ${ }^{1,2,3}$ and J.D. Obermiller ${ }^{1}$
}

ADDITIONAL INDEX WORDs. Malus $\times$ domestica, spray drift, spray coverage, biological efficacy, spray application technology, chemical thinning, sooty blotch, flyspeck

SUMMARY. A series of experiments was undertaken to compare the performance of an axial fan air blast sprayer equipped with air induction (AI) or conventional (C) nozzles in medium density apple (Malus $\times$ domestica) orchards. Performance was compared by assessing 1) spray coverage within the canopy at four levels of acrossrow wind speeds, 2) ground deposits from airborne drift under still conditions, and 3 ) biological efficacy of a postbloom thinning spray and a seasonal "high-risk" fungicide program where thiophanate methyl was not included. Spray coverage was reduced by up to $50 \%$ with increasing across-row wind speeds, the most dramatic reductions occurring between 0 and $4 \mathrm{mph}$ and at heights greater than $8 \mathrm{ft}$ in the canopy. AI nozzles resulted in a 2 -fold increase in spray coverage in the canopy of trees in the row immediately adjacent to the sprayer compared with $\mathrm{C}$ nozzles regardless of across-row wind speed. AI nozzles resulted in significantly less airborne drift compared with $\mathrm{C}$ nozzles under still conditions in an open field and within a mature 'Cripps Pink' / 'M.7' orchard planted in rows $20 \mathrm{ft}$ apart. Sprayer efficiency, measured as the proportion of total spray volume that was intercepted by the tree canopy, was higher for an airblast sprayer fitted with AI nozzles (38\%) than for C nozzles (26\%). The efficacy of a postbloom thinning spray (100 ppm benzyladenine plus carbaryl at $1 \mathrm{lb} / 100 \mathrm{gal}$ ) applied to 'Morgan Spur Red Delicious'/'M.111' trees planted at a between-row spacing of $15 \mathrm{ft}$ was slightly greater when applied with AI nozzles compared with C nozzles. However, application of a "high-risk" fungicide program with AI nozzles resulted in a higher incidence of fruit with flyspeck (Zygophiala jamaicensis) at harvest compared with C nozzles. These inconsistencies were related to the combined effects of nozzle type, orchard row spacing, and canopy density on spray deposition on trees in the second row from the sprayer or to possible effects of nozzle type on droplet density on the target. AI nozzles should provide equivalent or possibly improved coverage and biological efficacy compared with $\mathrm{C}$ nozzles in well-managed orchards planted at distances of $18 \mathrm{ft}$ or less between rows. However, when orchard rows are spaced greater than $18 \mathrm{ft}$ apart, AI nozzles will result in reduced spray coverage and chemical efficacy compared with $\mathrm{C}$ nozzles because of a reduction in spray carry-over to adjacent rows as a result of reduced airborne drift.

$\mathrm{M}$ ost common (apple) orchard sprayers in the United States are of the axial fan air-assist type configured with disc/whirl plate conventional spray nozzles producing fine droplets with a mean volumetric droplet

We thank Mr. Kenny Barnwell (RidgeView Apple Packers, Inc.) for his cooperation. This research was partially supported by a grant from the Washington Tree Fruit Research Commission.

Mention of a trademark, proprietary product, or vendor does not constitute a guarantee or warranty of the product and does not imply its approval to the exclusion of other products or vendors that may also be suitable.

${ }^{1}$ Department of Horticultural Science, North Carolina State University, Mountain Horticultural Crops Research and Extension Center, 455 Research Drive, Fletcher, NC 28732

${ }^{2}$ Southeast Apple Specialist (North Carolina, South Carolina, Georgia, Tennessee)

${ }^{3}$ Corresponding author. E-mail: steve_mcartney@ ncsu.edu. diameter within the range 200 to $300 \mu \mathrm{m}$ under normal operating pressures. Fine droplets produce more uniform spray coverage than coarse droplets, but are also more prone to off-target drift, even at moderate wind speeds (Fox et al., 1985, 1990). Spray drift becomes more of an issue as wind speed increases, reducing spray coverage and biological efficacy of costly crop protection materials and increasing the potential for human exposure and environmental contamination.

Air induction (AI) nozzles produce air-filled droplets with a mean volumetric diameter typically double that of conventional (C) nozzles (Frießleben, 2004; Heinkel et al., $2000)$ that behave in a ballistic manner, quickly falling to the ground once the air support drops below a critical value. AI nozzles are easily adapted to the axial fan sprayers of the type commonly used in the southeastern United States. Droplets produced by AI nozzles are less prone to drift than those produced by $\mathrm{C}$ nozzles (Guler et al., 2006; Jaeken et al., 2003; Jones et al., 2002; Ripke, 1999). The air-filled droplets produced by AI nozzles tend to fracture into many smaller droplets once they hit a solid surface, resulting in reduced bounce and increasing the potential for spreading on the target (Miller and Lane, 1999). Because of the behavior of droplets produced by AI nozzles, Heinkel et al. (2000) claimed they could be used in weather conditions that would result in the suboptimal performance of $\mathrm{C}$ nozzles such as high wind speed, low humidity, and high temperature.

Heinkel et al. (2000) reported equivalent penetration and biological efficacy of sprays for apple scab (Venturia inaequalis) and powdery mildew (Podosphaera leucotricha) when applied with orchard sprayers equipped with AI or hollow cone nozzles. A summary of 10 years of data comparing the biological efficacy of plant protection products using nozzles that produced coarse droplets (mean volumetric droplet size greater than $300 \mu \mathrm{m}$ ) or fine droplets (mean

\begin{tabular}{llll}
\hline $\begin{array}{l}\text { Units } \\
\text { To convert U.S. to SI, } \\
\text { multiply by }\end{array}$ & U.S. unit & SI unit & $\begin{array}{l}\text { To convert SI to U.S., } \\
\text { multiply by }\end{array}$ \\
\hline 0.3048 & $\mathrm{ft}$ & $\mathrm{m}$ & 3.2808 \\
3.7854 & $\mathrm{gal}$ & $\mathrm{L}$ & 0.2642 \\
9.3540 & gal/acre & $\mathrm{L} \cdot \mathrm{ha}^{-1}$ & 0.1069 \\
25.4 & inch(es $)$ & $\mathrm{mm}$ & 0.0394 \\
6.4516 & inch & $\mathrm{cm}^{2}$ & 0.1550 \\
1.1983 & lb/100 gal & $\mathrm{g} \cdot \mathrm{L}^{-1}$ & 0.8345 \\
1 & micron & $\mu \mathrm{m}$ & 1 \\
0.4470 & $\mathrm{mph}$ & $\mathrm{m} \cdot \mathrm{s}^{-1}$ & 2.2369 \\
1 & $\mathrm{ppm}$ & $\mathrm{mg} \cdot \mathrm{L}^{-1}$ & 1 \\
6.8948 & $\mathrm{psi}$ & $\mathrm{kPa}$ & 0.1450
\end{tabular}

Hartectunology $\cdot$ July-September 2008 18(3) 
volumetric droplet size less than 300 $\mu \mathrm{m})$ under commercial conditions concluded that nozzle type (i.e., droplet size) made little difference to biological performance when parameters such as choice of product, timing, and weather were optimum (Frießleben, 2004). However, Lesnik et al. (2005) reported a reduction in the efficacy of insecticides against codling moth (Cydia pomonella), green apple aphid (Aphis pomi), and a leaf miner (Leucoptera malifoliella) with AI nozzles compared with C nozzles. These comparative studies have tended to use cross-flow sprayers producing a planar air jet in highdensity orchard systems with a row spacing of 10 to $13 \mathrm{ft}$ and relatively narrow, single-leader tree canopies rather than the axial fan sprayers and medium-density orchard systems with row spacing ranging from 16 to $23 \mathrm{ft}$ typical of many apple production regions in the southeastern United States. In addition, most commercial evaluations of the biological efficacy of AI nozzles have been performed in dry continental climates where disease pressure is relatively low compared with the humid, high disease-pressure environments typical of production regions in the eastern United States. The objective of the present study was to compare the performance of $\mathrm{C}$ or AI nozzles fitted to an axial fan sprayer in medium density orchards in the southeastern United States.

\section{Materials and methods}

SPRAY COVERAge. A randomized complete block design experiment with three single-tree replications was conducted to compare the effects of AI or C nozzles at four levels of across-row wind speed on spray coverage in a mature 'Cripps Pink' / 'M.7' (M.7) orchard at the North Carolina State University Mountain Horticultural Crops Research Station in Fletcher, North Carolina. The trees were planted at a spacing of $20 \mathrm{ft}$ between rows and $10 \mathrm{ft}$ between trees within each row and trained to a central leader. The orchard sprayer was a power takeoff-driven, air assist axial fan sprayer (Streamliner 1500; Durand Wayland, LaGrange, GA) operated at a pressure of 100 psi with the nozzle configurations described in Table 1. AI nozzles producing a tapered-edge flat fan spray pattern (Spraying Systems, Wheaton, IL) were compared with disc/whirl plate combinations of $\mathrm{C}$ nozzles (Spraying Systems) producing a full cone spray pattern. The configuration of each nozzle type was designed to deliver the same total spray volume while matching the output at each nozzle position on the sprayer as closely as possible. At the orchard row spacing and a ground speed of $2 \mathrm{mph}$, the spray volume for each nozzle configuration was $168 \mathrm{gal} / \mathrm{acre}, 75 \%$ of the calculated orchard tree-row-volume according to the method described by Unrath (2002). Across-row wind speeds were generated with two identical air-assist axial fan sprayers (AF505; Durand Wayland) adjacent to the test tree as depicted in Fig. 1. "Low," "moderate," and "high" levels of wind speed were achieved by adjusting the fan speed on each tractor to generate maximum wind speed levels at the fan of 40,60 , and 80 $\mathrm{mph}$, respectively. Wind speeds resulting from each level were recorded at different heights in the canopy of three sample trees using a hand held anemometer (model 45160; Extech Instruments, Waltham, MA).

Spray coverage was assessed by image analysis of water-sensitive papers (WSP; Spraying Systems) stapled to the adaxial surface of three sample leaves at each of six heights in the canopy $(2,4,6,8,10$, and $12 \mathrm{ft})$. WSP were stapled to individual leaves rather than fixed to a vertical pole within the canopy so that their movement would mimic the natural movement of the attached leaf with each pass of the sprayer. Furthermore, attaching WSP to the same leaf for each nozzle configuration minimized potential sources of variability from differences between individual trees and canopy position within an individual tree. Although droplets with a mean diameter less than $100 \mu \mathrm{m}$ are not visible on WSP, neither of the nozzle types used in the present study produced droplets this small. WSP were collected after a single pass of the sprayer on only one side of the test tree. An 800-dot per inch (dpi) image of each WSP was created using a flatbed scanner (HP Scanjet 4070 Photosmart Scanner; Hewlett-Packard, Palo Alto, Ca). A representative area of each WSP at least $6 \mathrm{~cm}^{2}$ in area was cropped from each image and converted into an 8-bit per pixel black and white image using the IrfanView 4.00 software (Skiljan, 2007). Spray coverage was determined as the percentage of black pixels in the image

Table 1.Nozzle configuration and outputs (gal/min) at $100 \mathrm{psi}(689.5 \mathrm{kPa})$ for an air-assist axial fan orchard sprayer fitted with air induction or conventional nozzles.

\begin{tabular}{|c|c|c|c|c|c|}
\hline \multirow[b]{3}{*}{ Nozzle position } & \multicolumn{5}{|c|}{ Nozzle type } \\
\hline & \multicolumn{2}{|c|}{ Air Induction } & \multicolumn{3}{|c|}{ Conventional } \\
\hline & Nozzle & $\begin{array}{c}\text { Output } \\
(\text { gal } / \text { min })^{z}\end{array}$ & Disc & Core & $\begin{array}{c}\text { Output } \\
\text { (gal/min) }\end{array}$ \\
\hline 10 (highest) & - & - & - & - & - \\
\hline 9 & AIl105VS & 0.79 & D4 & DC35 & 0.79 \\
\hline 8 & AIl106VS & 0.95 & D4 & DC56 & 0.87 \\
\hline 5 & AIl106VS & 0.95 & D4 & DC56 & 0.87 \\
\hline 4 & AIl104VS & 0.63 & D4 & DC35 & 0.79 \\
\hline 3 & AIl103VS & 0.47 & D3 & DC56 & 0.53 \\
\hline 2 & AIl103VS & 0.47 & D3 & DC56 & 0.53 \\
\hline 1 (lowest) & - & - & - & - & - \\
\hline Total output (gal) & & 6.78 & & & 6.78 \\
\hline
\end{tabular}

${ }^{2} 1 \mathrm{gal}=3.7854 \mathrm{~L}$ 


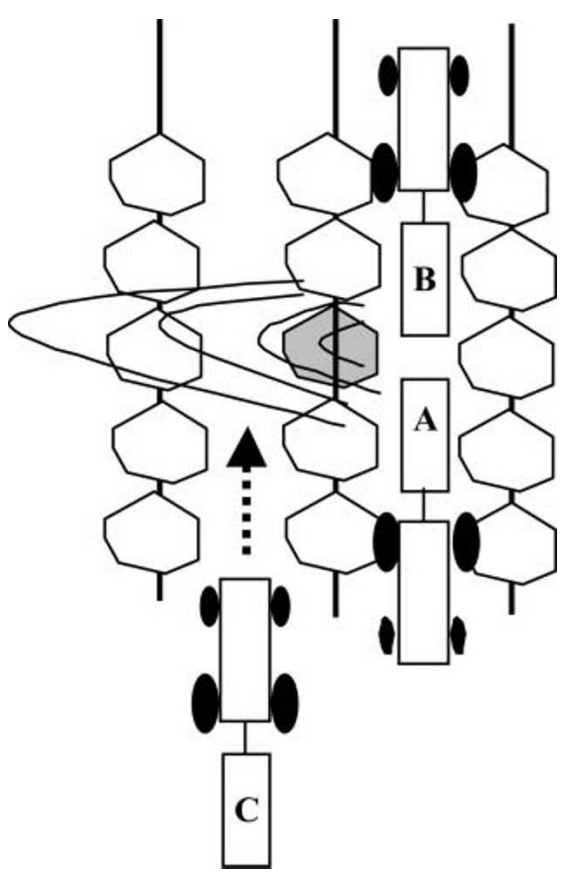

Fig. 1. Schematic representing how different levels of across-row wind speed were generated in the test apple orchard. Two identical air-assist axial fan sprayers (sprayers $A$ and $B$ ) were positioned back-to-back adjacent to the test tree (shaded) in the orchard. Fan speeds on sprayer A and sprayer B were regulated to achieve different levels of wind speed in the test tree. Sprayer C was configured with $\mathrm{AI}$ or $\mathrm{C}$ nozzles delivering an equivalent total spray volume. Foliar spray deposition was determined by placing three WSP at each of six different heights in the test tree.

using the UTHSCSA ImageTool program (University of Texas Health Science Center, 2002).

GROUND DEPOSITS FROM AIRBORNE DRIFT. The airborne drift resulting from each nozzle type was assessed in an open field and within the experimental orchard used in the spray coverage study. Airborne drift was quantified by fixing WSP onto wooden blocks placed on the ground at intervals of $5 \mathrm{ft}$ along a 70 - $\mathrm{ft}$ transect. There were three replicate transects for each nozzle type. Transects within the test orchard began in the center of the row being sprayed and consecutive rows centered at distances of $10,30,50$, and $70 \mathrm{ft}$ along each transect. Only a single pass of the sprayer was made at each location, with the tractor speed and sprayer output the same as that used in the coverage study. Airborne drift was quantified as the percentage of spray coverage on each WSP as in the previous experiment.

Biological EFFicacy. Two experiments were undertaken to evaluate the effects of AI and C nozzles on biological efficacy. The first was a chemical thinning study using mature 'Morgan Spur Red Delicious'/ 'M.111' (M.111) trees in a commercial orchard in Henderson County, North Carolina, planted in rows $15 \mathrm{ft}$ apart and trained to a central leader. The trees received a postbloom thinning spray of $100 \mathrm{ppm}$ 6-benzyladenine (6-BA) as the MaxCel formulation (Valent USA, Walnut Creek, CA) and $\mathrm{l} \mathrm{lb} / \mathrm{l} 00$ gal carbaryl as the Sevin XLR formulation (Bayer Crop Science, Research Triangle Park, NC) when the average fruit diameter was $7.1 \mathrm{~mm}$. The three treatments in the thinning study were an untreated control, and a postbloom thinning spray applied with an axial fan air assist sprayer (Smart Spray; Durand Wayland) configured with $\mathrm{AI}$ or $\mathrm{C}$ nozzles calibrated to deliver a spray volume of $150 \mathrm{gal} /$ acre. Thinning sprays were applied in still conditions during the midmorning when the relative humidity was between $60 \%$ and $70 \%$. Each treatment was applied to plots that were three adjacent rows wide to account for spray carry-over effects. Initial bloom counts were not taken; however, the trees in the study exhibited uniformly heavy bloom intensity. The number of fruit on each of six replicate trees was recorded after the completion of fruit drop. Thinning efficacy was expressed as fruit number per tree and crop density (fruit number $/ \mathrm{cm}^{2}$ trunk cross-sectional area). In the second comparison of nozzle type on biological efficacy, a seasonlong fungicide program was applied to plots within the same experimental 'Cripps Pink' / M.7 orchard as that used in the spray coverage and airborne drift studies. The configuration of AI and C nozzles, pump pressure, and ground speed were calibrated to deliver a spray volume of $205 \mathrm{gal} /$ acre. The fungicide thiophanate methyl (Topsin M; Cerexagri, King of Prussia, PA) has some eradicant activity against sooty blotch (a disease complex caused by Peltaster fructicola, Gaestrumia polystigmatis, Leptodontium elatius, and other fungi) and flyspeck and was excluded from the spray program to create a "high-risk" fungicide program that would increase the potential for development of these fruit diseases. Four replications of each treatment (nozzle type) were applied to 12 -tree plots (three adjacent rows with four trees in each), arranged in a randomized complete block design experiment. A random sample of 20 fruit was removed from the upper and lower canopy of the three center trees in each plot at harvest for assessment of the incidence of sooty blotch, flyspeck, or summer rots caused by bitter rot (Colletotrichum spp.) or white rot (Botryosphaeria dothidea). The effects of nozzle type and canopy position were analyzed using the GLM procedure of SAS (v9.1; SAS Institute, Cary, NC) after arcsine square root transformation of disease incidence data.

\section{Results and discussion}

Spray coverage. The two stationary air-assist axial fan sprayers generated a heterogeneous vertical profile of wind speed within the canopy of a tree $10 \mathrm{ft}$ away from the center of the fan; maximum wind speed measurements were recorded at heights of $6 \mathrm{ft}$ or less, whereas the lowest wind speed measurements were recorded at heights of 10 to $12 \mathrm{ft}$ as shown in Fig. 2. The same general heterogeneous wind speed profile within the tree was evident at each of the three generated wind speed levels. The maximum wind speeds recorded within the canopy were $4.0 \mathrm{mph}$ at $6 \mathrm{ft}$ for the low level, $6.9 \mathrm{mph}$ at $4 \mathrm{ft}$ for the moderate level, and $7.4 \mathrm{mph}$ at $4 \mathrm{ft}$ for the high level. Low, moderate, and high wind speed levels resulting in the canopy wind speed profiles described in Fig. 2 were the result of wind speeds measured at the fan outlet of 40,60 , and $80 \mathrm{mph}$, respectively. Thus, there was an approximately 10 -fold reduction in wind speed within a distance of $10 \mathrm{ft}$ from the fan outlet and the point of measurement in the center of the adjacent tree canopy. A similar reduction has been reported previously (Swiechowski et al., 2004).

Spray coverage was highest under still conditions, and coverage decreased with increasing across-row wind speed. The most pronounced reduction in spray coverage occurred between still conditions and the low wind speed level (Fig. 3), indicating 




Fig. 2. Effects of two stationary axial flow air-assist sprayers operated at three fan speeds (generating wind speeds of 40,60 , and $80 \mathrm{mph}$ at the fan for low, moderate, and high, respectively) on maximum across-row wind speeds measured at different heights within the canopy of mature 'Cripps Pink' / M.7 apple trees $10 \mathrm{ft}$ from the center of the fan. Data and horizontal bars represent mean values $\pm S E(n=3)$; $1 \mathrm{mph}=0.4470 \mathrm{~m} \cdot \mathrm{s}^{-1}, 1 \mathrm{ft}=0.3048 \mathrm{~m}$.

that coverage can be dramatically reduced even at relatively low wind speeds. The reduction in spray coverage with increasing wind speed was greater for C nozzles (46\%) than for AI nozzles (35\%). Spray coverage was increased $\approx 2$-fold by AI nozzles compared with $\mathrm{C}$ nozzles regardless of wind speed. Although the level of spray coverage resulting from $\mathrm{C}$ nozzles in the present study was similar to previously reported values (Jaeken et al., 2003), the greater coverage resulting from AI nozzles has not been reported elsewhere. Spray coverage resulting from AI nozzles under the high wind speed level was equivalent to the level of coverage that resulted from $\mathrm{C}$ nozzles under still conditions (Fig. 3), supporting the claim by Heinkel et al. (2000) that AI nozzles could be used in weather conditions that would result in the suboptimal performance of $\mathrm{C}$ nozzles.

The negative effect of increasing across-row wind speed on spray coverage was more pronounced higher in the canopy (Fig. 4). Because coverage data were collected from a single pass of the sprayer on only one side of the test trees, these results are somewhat different from might be expected when both sides of adjacent rows would be sprayed. However, high wind speeds would reduce spray coverage by an axial fan sprayer in the upper regions of the tree canopy

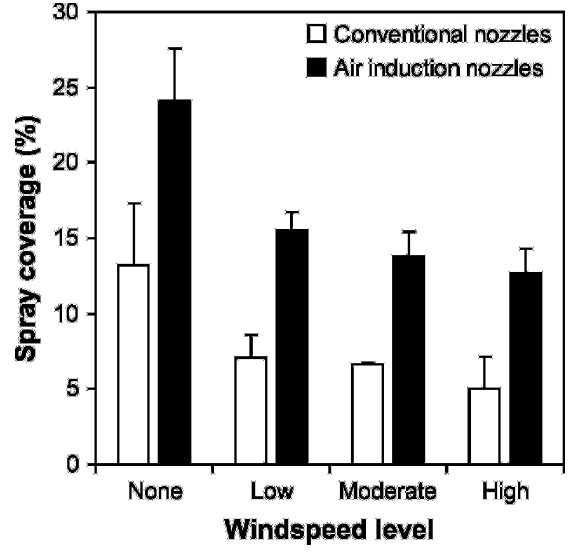

Fig. 3. Influence of nozzle type (AI or C) and across-row wind speed on spray coverage resulting from an axial fan air-assist spray application to mature 'Cripps Pink'/M.7 apple trees. The maximum wind speeds measured in the canopy for low, moderate, and high levels were 4.0, 6.9, and $7.4 \mathrm{mph}$ $\left(1.79,3.08\right.$, and $\left.3.31 \mathrm{~m} \cdot \mathrm{s}^{-1}\right)$, respectively. Coverage data were collected from the adaxial leaf surface after a single pass of the sprayer. Data are averages of three leaves at each of six different heights within the canopy. Vertical bars represent SE $(n=3)$.

regardless of wind direction. Although spray coverage resulting from AI nozzles should have been less affected by increasing wind speed levels, there was no evidence for this in the data collected at different heights in the tree canopy (Fig. 4, A-D). The data presented in Fig. 4 show that spray coverage from AI nozzles was at least equivalent to, and often greater than, spray coverage from $\mathrm{C}$ nozzles.

GROUND DEPOSITS FROM AIRBORNE DRIFT. AI and C nozzles produced distinct patterns of airborne drift in an open field and within the test orchard under still conditions. AI nozzles resulted in less airborne drift compared with $\mathrm{C}$ nozzles (Fig. 5), as has been previously reported (Guler et al., 2006; Jaeken et al., 2003; Ripke, 1999). Peak fallout from AI nozzles under still conditions occurred 20 and $15 \mathrm{ft}$ from the sprayer in an open field and within the test orchard, respectively, compared with 25 and $20 \mathrm{ft}$, respectively, for $\mathrm{C}$ nozzles. The peak in spray fallout from $\mathrm{C}$ nozzles within the test orchard coincided with the middle of the grass alleyway in the


Fig. 4. Influence of nozzle type on spray coverage at different heights within the canopy of mature 'Cripps Pink' /M.7 apple trees under no (A), low (B), moderate (C), or high (D) levels of across-row wind speed. The maximum wind speeds measured at a height of $6 \mathrm{ft}$ in the canopy for low, moderate, and high levels were $4.0,6.9$, and $7.4 \mathrm{mph}$ $\left(1.79,3.08\right.$, and $\left.3.31 \mathrm{~m} \cdot \mathrm{s}^{-1}\right)$, respectively. Coverage data were collected from the adaxial surface of three leaves at each height after spraying a single side. Data points are the means of three single tree replications $\pm S E ; 1 \mathrm{ft}=0.3048 \mathrm{~m}$. 


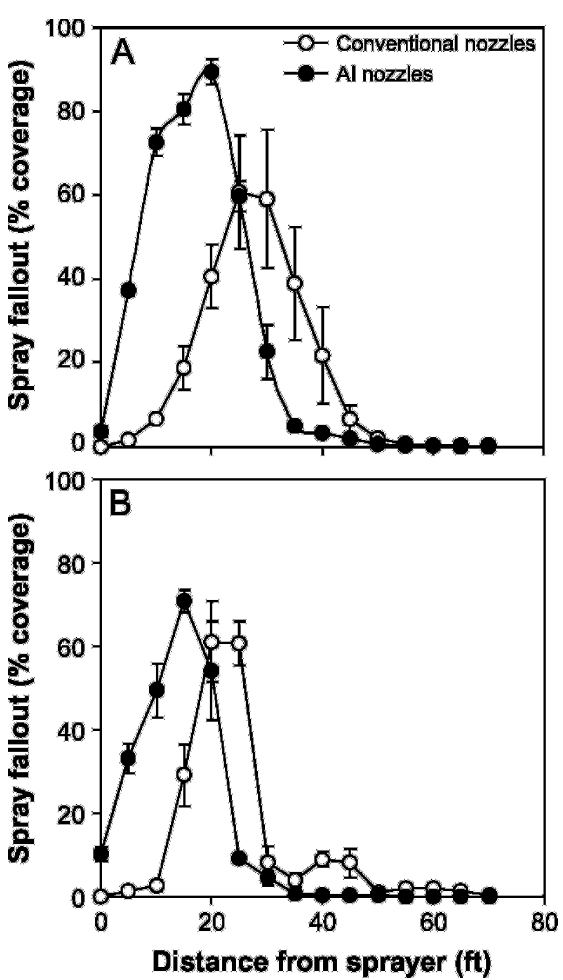

Fig. 5. Influence of nozzle type on ground deposits from airborne drift under still conditions in an open field (A) or within a mature 'Cripps Pink' / M.7 apple orchard planted at a between-row spacing of $20 \mathrm{ft}$ (B). Spray fallout was quantified as the percentage of spray coverage on WSP placed at 5 - $\mathrm{ft}$ intervals along a $70-\mathrm{ft}$ transect perpendicular to the direction of the sprayer. Data were collected after a single pass with the sprayer. Vertical bars represent \pm SE $(n=3)$; $1 \mathrm{ft}=0.3048 \mathrm{~m}$.

adjacent row. AI nozzles produced considerably more fallout of spray within the first $20 \mathrm{ft}$ from the sprayer compared with $\mathrm{C}$ nozzles under open field conditions (Fig. 5A), explaining why they also resulted in much better spray coverage within the canopy of trees in the row immediately adjacent to the sprayer (Fig. 3). This difference reflects the ballistic behavior of the larger droplets produced by AI nozzles, leaving the air support sooner than the smaller droplets produced by C nozzles, quickly falling onto the target or the ground. There was almost no fallout of spray from $\mathrm{C}$ nozzles within the first $10 \mathrm{ft}$ from the sprayer in an open field, but considerable spray fallout occurred 15 to $40 \mathrm{ft}$ from the sprayer. There was no drift of spray droplets from either nozzle type beyond $50 \mathrm{ft}$ from the sprayer under still conditions.
The pattern of airborne drift for each nozzle type was subtly different within the test orchard (Fig. 5B) compared with an open field (Fig. $5 \mathrm{~A}$ ). The peak of spray fallout from either nozzle type occurred $5 \mathrm{ft}$ closer to the sprayer within the orchard compared with an open field, reflecting the dampening effect of the tree canopy itself on the level of air support. Ground deposits resulting from airborne drift will be less within an orchard compared with an open field; the difference reflecting the amount of spray intercepted by the tree canopy. This calculation then provides a measure of the overall efficiency of the sprayer system. Spray interception was $38 \%$ for AI nozzles compared with only $26 \%$ for $\mathrm{C}$ nozzles, indicating that fitting an axial fan sprayer with AI nozzles resulted in a greater proportion of the total spray volume reaching the intended target in the test orchard compared with $\mathrm{C}$ nozzles. A similar trend across different orchard systems (combinations of rootstocks, row spacings, planting densities, and training methods), would translate into a reduced risk for environmental contamination with AI nozzles. Estimates of spray interception in the mature apple orchard in the current study are $\approx 50 \%$ lower than values previously reported for a mature pecan (Carya illinoinensis) orchard where the tree height was $11 \mathrm{~m}(36.1 \mathrm{ft}$; Miller et al., 2003). Curiously, C nozzles resulted in greater ground deposits at distances of 15 and $20 \mathrm{ft}$ from the sprayer within the test orchard compared with under open field conditions, coinciding with the middle of the next row over from the sprayer. The increased spray fallout at this distance was presumably the result of a dampening effect of the tree canopy on the level of air support, causing it to fall below a critical value for the smaller droplets generated by $\mathrm{C}$ nozzles.

The two nozzle types differed in the amount of spray drift that was deposited 25 to $35 \mathrm{ft}$ from the sprayer, corresponding to the canopy of trees in the second row from the sprayer in the test orchard. AI nozzles resulted in little or no carry-over of spray to trees in the second row from the sprayer $(25-35 \mathrm{ft})$ whereas there was significant drift from $\mathrm{C}$ nozzles at these distances in an open field (Fig. $5 \mathrm{~A}$ ). There was a depression in spray fallout from $\mathrm{C}$ nozzles in the orchard that occurred between 25 and $40 \mathrm{ft}$ from the sprayer (Fig. 5B) that can be explained by interception of spray by the canopy of the tree in the second row from the sprayer. Alternate row spraying is a relatively common practice on commercial apple orchards in the southeast, particularly during the early stages of the growing season (up until application of the second cover spray) when the tree canopies are still relatively open. Because the amount of spray drift from AI nozzles declined rapidly at distances greater than $20 \mathrm{ft}$ from the sprayer, they could not be recommended for alternate row spraying unless the rows were 13 to $14 \mathrm{ft}$ apart or less.

Biological EFFiCACY. A postbloom thinning spray of 6-BA plus carbaryl reduced the number of fruit per tree and the crop density relative to an unthinned control (Table 2). AI nozzles resulted in a slight increase in thinning efficacy compared with $\mathrm{C}$ nozzles. This response may have resulted from an increased carry-over of thinning spray onto trees in the second row over from the sprayer with AI nozzles, particularly because the rows in this orchard were planted at a spacing that was coincident with the peak distance of spray fallout from the sprayer (Fig. 5).

There was a high incidence of fruit with sooty blotch and flyspeck at harvest in the fungicide efficacy study, presumably resulting from the omission of thiophanate methyl from the spray program. The incidence of sooty blotch, flyspeck, and summer rots was higher in fruit from trees that had been sprayed with AI nozzles compared with C nozzles, although this increase was statistically significant for flyspeck only (Table 3). Because spray coverage was higher with AI nozzles compared with $\mathrm{C}$ nozzles (Fig. 3), it is unclear why they would also result in a higher incidence of fruit with flyspeck at harvest. Assessments of spray coverage after a single pass of the sprayer (Fig. 3) would result in an underestimation of spray coverage from $\mathrm{C}$ nozzles compared with multiple passes of contiguous rows because it would not account for the additional coverage resulting from spray carryover. The contribution of spray carryover to total spray coverage was not quantified in the present study, 
Table 2.Comparative efficacy of a postbloom thinning spray of $100 \mathrm{ppm}$ $\left(\mathrm{mg} \cdot \mathrm{L}^{-1}\right)$ 6-BA plus $1 \mathrm{lb} / 100 \mathrm{gal}\left(1.2 \mathrm{~g} \cdot \mathrm{L}^{-1}\right)$ carbaryl applied to mature 'Morgan Spur Red Delicious' /M.111 apple trees with an axial fan air assist orchard sprayer equipped with air induction $(\mathrm{AI})$ or conventional $(\mathrm{C})$ nozzles.

\begin{tabular}{lcc}
\hline & Fruit (no./tree) & Crop density (fruit $/ \mathrm{cm}^{2}$ trunk area $)^{\mathbf{z}}$ \\
\cline { 2 - 3 } Treatment & \multicolumn{1}{c}{ Mean \pm SE $(\mathbf{n}=\mathbf{6})$} \\
\hline Unthinned control & $306 \pm 20$ & $4.7 \pm 0.3$ \\
AI nozzles & $148 \pm 15$ & $2.4 \pm 0.2$ \\
C nozzles & $189 \pm 14$ & $3.2 \pm 0.3$ \\
\hline
\end{tabular}

${ }^{2} 1$ fruit $/ \mathrm{cm}^{2}=6.4516$ fruit $/ \mathrm{inch}^{2}$.

Table 3.Effect of air induction (AI) or conventional (C) nozzles on efficacy of fungicide sprays applied to 'Cripps Pink' /M.7 apple trees to control sooty blotch, flyspeck, and summer rots on fruit. Fruit were sampled at two different heights in the canopy at harvest. Disease incidence data were arcsine square root transformed before analysis. Data are back-transformed means.

\begin{tabular}{lccc}
\hline & \multicolumn{3}{c}{ Disease incidence (\%) } \\
\cline { 2 - 4 } Treatment & Sooty blotch & Flyspeck & Summer rots \\
\hline Nozzle type & 44 & 68 & 11 \\
$\quad$ Air induction & 35 & 46 & 5 \\
$\quad$ Conventional & & & \\
Canopy position & 25 & 34 & 12 \\
$\quad$ Lower & 55 & 79 & 4 \\
$\quad$ Upper & & & NS \\
Significance & $\mathrm{NS}$ & $* * *$ & $*$ \\
$\quad$ Nozzle type & $*$ & $\mathrm{NS}$ & $\mathrm{NS}$ \\
$\quad$ Canopy position & $\mathrm{NS}$ & & \\
Interaction & & &
\end{tabular}

Ns, ${ }^{*}{ }^{* * *}$ Nonsignificant or significant at $P \leq 0.05$ or 0.001 , respectively.

although it is difficult to imagine that carry-over of spray from $\mathrm{C}$ nozzles would result in the (approximate) doubling of spray coverage needed to result in a level of coverage equivalent to AI nozzles (Fig. 3). Alternatively, an increased efficacy of fungicides when applied with $\mathrm{C}$ nozzles compared with AI nozzles despite a reduced spray coverage may be related to factors such as the density of spray droplets on the target and the zone of fungal inhibition around each droplet. Washington (1997) demonstrated that the efficacy of protectant fungicide sprays was influenced by the droplet density, and that different fungicides had different zones of inhibition surrounding individual droplets. Although droplet density for each nozzle type was not measured in the current study, it is possible that the smaller droplets produced by $\mathrm{C}$ nozzles may have resulted in higher droplet densities and a more uniform spray deposition on the fruit surface. There was a significant effect of canopy position on the incidence of fruit with all three fungal pathogens; sooty blotch and flyspeck were more prevalent in the upper part of the tree canopy, whereas summer rots were more prevalent in the lower tree canopy.

\section{Conclusions}

This research demonstrates that AI nozzles reduced airborne drift, increased spray coverage in the row immediately adjacent to the sprayer, and resulted in greater interception of the total spray volume by the target compared with $\mathrm{C}$ nozzles. We found that the efficacy of a chemical thinning spray was increased when applied with AI nozzles, consistent with their effects on spray coverage. However, we also found that the efficacy of a seasonal fungicide spray program was reduced when it was applied with AI nozzles compared with $\mathrm{C}$ nozzles. These inconsistencies were related to the combined effects of nozzle type and orchard row spacing on spray deposition on trees in the second row from the sprayer or to possible effects of nozzle type on droplet density on the target. At a between-row spacing of $20 \mathrm{ft}$ or more, the drift profile from AI nozzles results in peak fallout of spray in the grass alleyway, with little or no spray reaching the canopy of trees in the next row. When the between-row spacing is 10 to $14 \mathrm{ft}$, AI nozzles will result in considerable spray deposition onto trees in the next row. The positive effects of AI nozzles on drift reduction and spray coverage in trees in the row immediately adjacent to the sprayer under even moderate wind speeds will need to be balanced against a reduction in spray deposition on trees in the next row when the between-row spacing is greater than $15 \mathrm{ft}$.

\section{Literature cited}

Fox, R.D., D.L. Reichard, and R.L. Brazee. 1985. A model study of the effect of wind on air sprayer jets. Trans. Amer. Soc. Agr. Eng. 28:83-88.

Fox, R.D., D.L. Reichard, R.L. Brazee, and F.R. Hall. 1990. Downwind residue from air spraying of a dwarf apple orchard. Trans. Amer. Soc. Agr. Eng. 33:11041108.

Frießleben, R. 2004. Balancing drift management with biological performance and efficacy. 13 Sept. 2007. <http://pep. wsu.edu/Drift04/pdf/proceedings / pg72-79_Frie\%DFleben.pdf>.

Guler, H., H. Zhu, H.E. Ozkan, R.C. Derksen, Y. Yu, and C.R. Krause. 2006. Spray characteristics and wind tunnel evaluation of drift reduction potential with air induction and conventional flat fan nozzle. Amer. Soc. Agr. Biol. Eng., Annu. Intl. Mtg., Paper No. 06111. (Abstr.)

Heinkel, R., A. Fried, and E. Lange. 2000. The effect of air injector nozzles on crop penetration and biological performance of fruit sprayers. Aspects Appl. Biol. 57:301-307.

Jaeken, P., L. De Maeyer, N. Broers, and P. Creemers. 2003. Nozzle choice and its effect on spray deposit and distribution, uptake, drift and biological efficacy in standard apple orchards (Malus sylvestris, cv Jonagold). Pflanzenschutz Nachrichten Bayer 56:326-353.

Jones, E.J., J.E. Hanks, and G.D. Wills. 2002. Effect of different nozzle types on drift and efficacy of Roundup Ultra. Mississippi Agr. For. Expt. Sta. Bull. 1119.

Lesnik, M., C. Pintar, A. Lobnik, and M. Kolar. 2005. Comparison of the effectiveness of standard and drift-reducing nozzles for control of some pests of apple. Crop Prot. 24:93-100. 
Miller, D.R., E.W. Huddleston, J.B. Ross, and W.E. Steinke. 2003. Airblast spray partitioning in a mature pecan orchard. Trans. Amer. Soc. Agr. Eng. 46:14951501.

Miller, P.C.H. and A.G. Lane. 1999. Relationship between spray characteristics and drift risk into field boundaries of different structure. Aspects Appl. Biol. 54:45-51.

Ripke, F.O. 1999. Weniger Abstand zum Gewässer. DLG-Mitteilungen $8: 44-45$.
Skiljan, I. 2007. IrfanView version 4.00. 2 Nov. 2007. <http://www.irfanview. $\mathrm{com} />$.

Swiechowski, W., G. Doruchowski, R. Holownicki, and A. Godyn. 2004. Penetration of air within the apple tree canopy as affected by the air jet characteristics and travel velocity of the sprayer. 13 Sept. 2007. <http://www.ejpau.media.pl/ series/volume7/issue2/engineering/art03.html>.

University of Texas Health Science Center. 2002. UTHSCSA ImageTool, ver- sion 3.0. 2 Nov. 2007. <http:// ddsdx.uthscsa.edu/dig/itdesc.html>.

Unrath, C.R. 2002. Spray volume, canopy density, and other factors involved in thinner efficacy. HortScience 37:481-483.

Washington, J.R. 1997. Relationship between the spray droplet density of two protectant fungicides and the germination of Mycosphaerella fijiensis ascospores on banana leaf surfaces. Pestic. Sci. 50:233239. 